\title{
Special features of high-risk pregnancies as factors in development of mental distress: a review
}

\author{
Particularidades da gravidez de alto risco como fatores para \\ o desenvolvimento de sofrimento mental
}

Paula Borba Rodrigues, Carla Fonseca Zambaldi, Amaury Cantilino, Everton Botelho Sougey*

\begin{abstract}
Introduction: Approximately $22 \%$ of all pregnant women are classified as having high-risk pregnancies, which may involve feelings of vulnerability because of having a high-risk pregnancy, resulting in greater exposure to stressful feelings.

Objective: To review aspects of high-risk pregnancy that can have a negative impact on the these women's mental health status.

Method: Original articles were identified by conducting searches of the PubMed/MEDLINE, LILACS and SciELO databases, followed by a manual search of references to select articles and additional bibliographic material. Articles from the last 22 years were included in the review (1992-2014).

Results: Fifteen articles were found that specifically studied high-risk pregnancies and mental health outcomes. Women with high-risk pregnancies exhibited a significantly higher level of stress and reported negative emotions as they dealt with stress and had worse emotional status than women with normal pregnancies. Researchers found that hospitalized pregnant women had higher levels of anxiety than non-hospitalized women. Studies of women going through normal and high-risk pregnancies show that women with normal pregnancies had good self-perceived quality of life.

Conclusion: Special features of high-risk pregnancies could be factors in development of mental distress, in addition to psychological and social factors. Therefore, only a biopsychosocial research study would be able to identify the factors that can affect the quality of mental health during high-risk pregnancy. Keywords: High-risk pregnancy, mental disorder, depression, anxiety, risk.
\end{abstract}

\section{Resumo}

Introdução: Aproximadamente $22 \%$ de todas as mulheres grávidas são classificadas como tendo gravidezes de alto risco, podendo experimentar vulnerabilidade por esta situação. Desta forma, estão mais expostas a sentimentos de estresse.

Objetivo: Revisar aspectos da gravidez de alto risco que podem ter um impacto negativo sobre o estado de saúde mental dessas mulheres. Métodos: Artigos originais foram localizados por meio de uma busca eletrônica nas bases de dados PubMed/MEDLINE, LILACS e SciELO, bem como uma busca manual de referências para selecionar artigos e material bibliográfico adicional. Foram selecionados artigos publicados nos últimos 22 anos (1992-2014).

Resultados: Foram encontrados 15 artigos que estudavam especificamente gravidez de alto risco e o desfecho saúde mental. Mulheres grávidas de alto risco demonstraram um nível significativamente mais elevado de estresse e relataram emoções negativas ao lidar com o estresse; elas também apresentavam pior estado emocional quando comparadas a mulheres com gravidez normal. Os pesquisadores observaram que as mulheres grávidas internadas tinham níveis mais elevados de ansiedade do que mulheres não hospitalizadas. Outros estudos envolvendo mulheres com gestações normais e de alto risco mostram que as mulheres com uma gravidez normal têm uma boa percepção de sua qualidade de vida. Conclusões: As particularidades das gestações de alto risco, além de fatores psicológicos e sociais, podem ser fatores no desenvolvimento de transtornos mentais. Portanto, somente um estudo biopsicossocial seria capaz de identificar os fatores que podem afetar a qualidade da saúde mental durante a gravidez de alto risco.

Descritores: Gravidez de alto risco, doença mental, depressão, ansiedade, risco.

\footnotetext{
* Departamento de Neuropsiquiatria, Universidade Federal de Pernambuco (UFPE), Recife, PE, Brazil. Financial support: none.

Submitted Oct 17 2015, accepted for publication Jun 07 2016. No conflicts of interest declared concerning the publication of this article.

Suggested citation: Rodrigues PB, Zambaldi CF, Cantilino A, Sougey EB. Special features of high-risk pregnancies as factors in development of mental distress: a review. Trends Psychiatry Psychother. 2016;38(3):136-140. http://dx.doi.org/10.1590/2237-6089-2015-0067
} 


\section{Introduction}

High-risk pregnancies affect a significant number of women each year. Approximately $22 \%$ of all pregnant women are classified as having high-risk pregnancies. ${ }^{1}$ A high-risk pregnancy is defined as any pregnancy in which there is evidence of actual or potential threat of harm to the life or health of the mother and/or the baby because of a disorder or situation coincidental with or unique to pregnancy. ${ }^{2}$ Women going through high-risk pregnancies may require complex care involving lifestyle modifications, pharmacological and technical support and even hospitalization. As a result, these women may experience feelings of vulnerability because they have a high-risk pregnancy and thus be more exposed to stressful feelings. ${ }^{2}$ Research into the social and psychological aspects of high-risk pregnancies has focused on the concerns, stressors and needs of women with high-risk pregnancies during the antepartum period. ${ }^{3}$

One aspect of research into stress in high-risk pregnancy is that it has indicated that the high-risk label results in additional stress for women. ${ }^{4}$ Health-care providers often consider the high-risk pregnancy label to be an indication that a woman and/or her unborn infant are at risk because of a medical or obstetric condition. One interpretation of the stress is that once a woman is categorized as high-risk, concerns may focus more on medications and tests and less on the woman herself. Another interpretation is that pregnant women labeled as high-risk might respond to the label because of societal expectations. ${ }^{1}$

Women with a high-risk pregnancy are often subjected to emergency hospitalization and threats to themselves and to their fetuses that have an adverse impact on both themselves and their families. ${ }^{5}$ When the severity of maternal complications increases, women are hospitalized for increased medical surveillance and intervention, including antepartum bed rest. Bed rest during pregnancy is sometimes prescribed to help prevent complications, but bed rest itself is associated with numerous physiological and psychosocial changes that alter the functions of every major organ system. ${ }^{6}$ Several studies have reported that hospitalized women were significantly more depressed than women in other groups with whom they were compared. ${ }^{7,8}$

With regard to the perception of risk, research findings suggest that if a woman perceives an above-average total risk to herself and her infant, she will experience increased levels of uncertainty, higher psychological distress and reduced well-being. Therefore, the more a woman perceives her infant or herself to be at risk, the more likely she is to experience increased stress, irrespective of whether the risk is real or perceived. ${ }^{2}$
The objective of this study was to review special features of high-risk pregnancies that can have a negative impact on these women's mental health status, such as mental distress, interventions for rest or hospitalization, the high-risk label itself and the risk perceived by pregnant women.

\section{Method}

\section{Search strategy}

Papers were primarily identified by searching online electronic databases using the following terms: mental disorder OR "high-risk pregnancy" AND distress OR depression OR anxiety OR perception of risk.

Original articles were located by conducting searches of the PubMed/MEDLINE, LILACS and SciELO databases, followed by an additional manual search for references to identify articles and additional bibliographic material on the subject, such as dissertations, books and scientific journal articles. Articles from the last 22 years were included (1992-2014).

\section{Inclusion and exclusion criteria}

Articles covering topics related to mental distress/ disorders in high-risk pregnant women and their implications for this risk group were included in the review. The study was restricted to articles in English and Portuguese. Only studies involving human beings were included. Articles were excluded if they only covered high-risk pregnancy, without relating it to aspects of mental stress or disorders.

\section{Results and discussion}

A total of 130 articles published between 1992 and 2014 were initially identified using the descriptors and parameters outlined above. The titles and abstracts of these articles were reviewed and the full texts of articles were read whenever necessary. Eight articles were found to be repeats resulting from the combination of different descriptors, and were therefore excluded. Of the remainder, 28 articles were considered potentially eligible on the basis of title or abstract. Thirteen articles were excluded because their research focus was obstetric and non-psychiatric or because they discussed low-risk pregnancy, pregnancy complications or other pregnancy conditions. Finally, 15 articles were found that specifically studied high-risk pregnancy and mental health outcomes (Figure 1). 


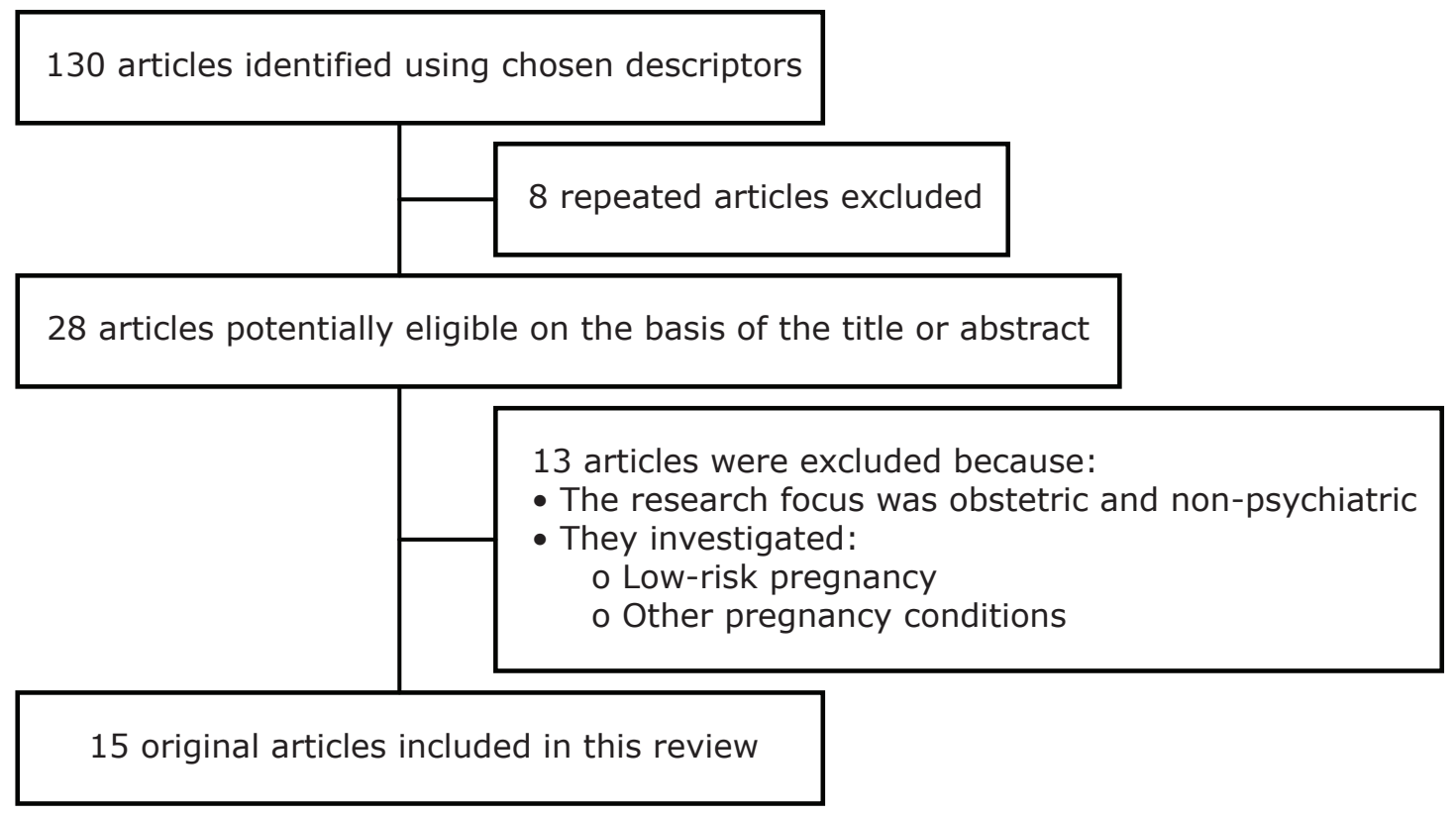

Figure 1 - Flowchart illustrating the article selection process for this review.

The list of articles included in the review is shown in Table 1. A narrative review describing their results follows.

Table 1 - Overview of the studies included in the review

\begin{tabular}{|c|c|c|c|}
\hline Study & Location & Year & Feature of high-risk pregnancy \\
\hline Maloni et al. ${ }^{9}$ & USA & 1993 & Antepartum bed rest \\
\hline Mccain \& Deatrick ${ }^{3}$ & USA & 1994 & Experience of high risk pregnancy \\
\hline Heaman \& Gupton ${ }^{7}$ & Canada & 1998 & Perception of bed rest \\
\hline Gupton et al. ${ }^{10}$ & Canada & 2001 & Perception of risk \\
\hline Maloni et al. ${ }^{8}$ & USA & 2002 & Pregnant women on bed rest \\
\hline Maloni et al. ${ }^{5}$ & USA & 2005 & Antepartum depressive symptoms \\
\hline Rumbold \& Crowther ${ }^{11}$ & Australia & 2002 & Gestational diabetes \\
\hline Stahl \& Hundley ${ }^{4}$ & Germany & 2003 & High-risk label \\
\hline El-Kak et al. ${ }^{12}$ & Lebanon & 2004 & Antepartum care \\
\hline Gray $^{2}$ & USA & 2006 & Hospitalization \\
\hline Simmons \& Goldberg ${ }^{1}$ & Canada & 2011 & Perinatal loss \\
\hline Maloni et al. ${ }^{6}$ & USA & 2011 & Antepartum bed rest \\
\hline Benute et al. ${ }^{13}$ & Brazil & 2011 & Suicide \\
\hline Rodrigues $^{14}$ & Brazil & 2011 & Common mental disorder \\
\hline Thiagayson et al. ${ }^{15}$ & Singapore & 2013 & Depression and anxiety \\
\hline
\end{tabular}

\section{High-risk pregnancy and mental distress/ disorders}

One study evaluating the experience of high-risk pregnancy described the emotional responses to high-risk pregnancy events as reported by the parents involved, as follows: vulnerability of pregnancy, the realization that the pregnancy outcome was at risk; heightened anxiety, since normal activities were restricted because of medical symptoms; and the inevitability of premature delivery, with realization that preterm labor and delivery were imminent. Women who had had a high-risk pregnancy demonstrated a significantly higher level of stress and related negative emotions as they dealt with the stress and worse emotions than women with normal pregnancies. ${ }^{3}$ Additionally, a higher intensity of depression symptoms during pregnancy 
was observed in a group of high-risk pregnant women. ${ }^{4}$ Regarding reproductive health status, another study found that stress and anxiety are associated with increased risk of preterm birth and low birth weight. ${ }^{10}$

In Brazil, a study assessing the risk of suicide in highrisk pregnancies found that $5 \%(n=14)$ of the total sample of pregnant women being managed for high-risk pregnancy had a specific risk for suicide. It was reported that they thought it would be better to die or be injured in some way, considering a 15-day period prior to the date of the interview. ${ }^{13}$ Still in Brazil, another study found that $18.3 \%$ ( $n=28$ ) of the total sample of high-risk pregnant women reported the symptoms "thoughts of ending your life."14

Contradicting these results, a study of women's experiences of being screened for gestational diabetes mellitus found no differences in anxiety or depression scores between women with negative or positive screening results. ${ }^{11}$

More recently, another study aimed to establish the prevalence of antenatal depression and anxiety in highrisk pregnancies, as well as to compare the prevalence of antenatal depression in high-risk pregnancies vs. pregnancies of unspecified obstetric risk and found that major depression was more prevalent in high-risk pregnancies than it was in the historical cohort of unspecified obstetric risk (11 vs. $4.3 \%) .{ }^{15}$

\section{Hospitalized pregnant women on bed rest}

Bed rest is associated with numerous physiological and psychosocial changes that alter the function of every major organ system including slowing of electroencephalographic waves, dulling of cortical processes, and alterations to cognition, affect, and perception. ${ }^{6}$

In a longitudinal study, women on complete bed rest had significantly greater dysphoria than women on partial or no bed rest, which decreased over time. ${ }^{9}$ Additionally, antepartum bed rest treatment was accompanied by maternal feelings of intense fear, lack of control, powerlessness, anger, and anxiety. In another study of 63 women, the authors confirmed the decrease in depressive symptoms from hospital admission to 6 weeks postpartum in women on partial bed rest. ${ }^{8}$ In Canada, researchers found that hospitalized pregnant women had higher levels of anxiety than non-hospitalized women and that stressful life events were positively related to anxiety. In general, women experiencing high-risk pregnancy have higher levels of stress and anxiety. ${ }^{7}$

\section{Label of high-risk and perception of risk}

A Canadian study about high-risk pregnancy after perinatal loss found that women living through high-risk pregnancy subsequent to a perinatal loss experience not only the "normal" uncertainty associated with pregnancy, but also the uncertainty of whether or not their pregnancy will result in a healthy infant. ${ }^{1}$ Given the degree of uncertainty experienced by these women and that obstetricians are often seen as experts in pregnancy and unborn infants, it is perhaps understandable why women experiencing high-risk pregnancy subsequent to perinatal loss may see obstetricians as a "perfect" resource that would increase their chance of taking a living infant home. In addition to being a resource, the obstetrician validates the woman's pregnancy as "special" by labeling the pregnancy as high-risk and increasing vigilance. All the participants expressed positive sentiments for both the health-care providers and the technology associated with the label of high-risk pregnancy. Likewise, if they acknowledged any negative thoughts about their healthcare providers or their care, they may have felt like they would be tempting fate for something to go wrong. Other studies support this conclusion and argue that doctors are in a position of power, and that technology often objectifies the woman's experience, setting the woman up to be alienated from her own pregnancy. ${ }^{1,4}$

On the other hand, in a study of pregnant women prior to and after being screened for gestational diabetes mellitus, women with positive screening results had poorer health perceptions than women with negative screening results. ${ }^{11}$ However, these differences were not evident late in pregnancy. Similarly, women with negative screening results were more likely to rate their health as "much better than one year ago" than women with positive screening results. No differences were found between groups regarding the concern shown for the health of their newborn either after screening or late in pregnancy.

\section{Quality of life in high-risk pregnancy}

Poor fetal outcome (assessed by the presence of at least 1 neonatal problem) was associated with fewer antenatal visits among women residing in Beirut. ${ }^{12}$ With regard to maternal and neonatal outcomes, their data suggest that additional antenatal visits might have a protective effect. These visits allowed earlier and better detection of possible obstetric (maternal) and psychosocial problems, and consequently better management, resulting in fewer cases of depression or preterm delivery, better neonatal outcomes, and more caesarean sections. ${ }^{12}$ However, these findings can also be found in studies of women with lowrisk pregnancies.

\section{Conclusions}

In these concluding remarks, we begin by revealing limitations caused by the small number of articles 
addressing at-risk pregnancies. Studies are scarce and small sample sizes and methodological differences contribute to a situation in which results are still unreliable. Notwithstanding, we can still conclude that many aspects are involved in being a high-risk pregnant woman, ranging from the actual obstetric implications to psychological and social factors. Overall, the results of research are highly variable and there is a need to further clarify many issues.

Fearful expectations regarding the outcomes for the mother and/or the baby seem to be related to increased vulnerability to developing stress reactions and other psychiatric disorders. It seems clear that the high-risk label has implications from the perspective of the team treating these women, and as perceived by the pregnant woman herself or her family. However, there was no indication in the research as to why the label of highrisk pregnancy resulted in additional stress. Trusting the obstetrician with regards to a safe prenatal period and having regular consultations and information about the delivery being available are supportive measures that help with coping with a high-risk pregnancy.

The mother's perception of risk also seems to be a relevant factor in emergence of stressful feelings. However, it was observed that women with complicated pregnancies might make an appraisal of risk regardless of, and sometimes divergent from, the risk status determined by health care practitioners. ${ }^{10}$ Limited information exists on how these women appraise the risk to their pregnancy.

In view of these findings, we suggest that mental disorders should be routinely investigated during highrisk pregnancy, whenever possible with the use of specific instruments so that they can be detected early and so that interventions can be made in due time. Therefore, only a biopsychosocial research study would be able to identify factors that might affect the quality of mental health during pregnancy.

\section{References}

1. Simmons HA, Goldberg LS. 'High-risk' pregnancy after perinatal loss: understanding the label. Midwifery. 2011;27:452-7.

2. Gray BA. Hospitalization history and differences in self-rated pregnancy risk. West J Nurs Res. 2006;28:216-29.

3. Mccain GC, Deatrick JA. The experience of high-risk pregnancy. J Obstet Gynecol Neonatal Nurs. 1994;23:421-7.

4. Stahl K, Hundley V. Risk and risk assessment in pregnancy - do we scare because we care? Midwifery. 2003;19:298-309.

5. Maloni JA, Park S, Anthony MK, Musil CM. Measurement of antepartum depressive symptoms during high-risk pregnancy. Res Nurs Health. 2005;28:16-26.

6. Maloni JA. Lack of evidence for prescription of antepartum bed rest. Expert Rev Obstet Gynecol. 2011;6:385-93.

7. Heaman M, Gupton A. Perceptions of bed rest by women with high-risk pregnancies: a comparison between home and hospital. Birth. 1998;252:8.

8. Maloni JA, Kane JH, Suen LJ, Wang KK. Dysphoria among highrisk pregnant hospitalized women on bed rest: a longitudinal study. Nurs Res. 2002;51:92-9.

9. Maloni JA, Chance B, Zhang C, Cohen AW, Betts D, Gange SJ. Physical and psychosocial side effects of antepartum hospital bed rest. Nurs Res. 1993;42:197-203.

10. Gupton A, Heaman M, Cheung LW. Complicated and uncomplicated pregnancies: women's perception of risk. J Obstet Gynecol Neonatal Nurs. 2001;30:192-201.

11. Rumbold AR, Crowther CA. Women's experiences of being screened for gestational diabetes mellitus. Aust N Z J Obstet Gynaecol. 2002;42:131-7.

12. El-Kak F, Chaaya M, Campbell O, Kaddour A. Patterns of antenatal care in low versus high-risk pregnancies in Lebanon. East Mediterr Health J. 2004;10:268-76.

13. Benute GRG, Nomura RMY, Jorge VMF, Nonnenmacher D, Fraguas Junior R, Lucia MCS de, et al. Risco de suicídio em gestantes de alto risco: um estudo exploratório. Rev Assoc Med Bras. 2011;57:538-7.

14. Rodrigues PAB. Transtorno mental comum em gestantes de alto risco: primeiro estudo de prevalência [dissertation]. Recife: Universidade Federal de Pernambuco; 2011.

15. Thiagayson P, Krishnaswamy G, Lim ML, Sung SC, Haley CL, Fung DS, et al. Depression and anxiety in Singaporean high-risk pregnancies - prevalence and screening. Gen Hosp Psychiatry. 2013;35:112-6.

\section{Correspondence:}

Paula Borba Rodrigues

Rua Dom José Tomaz, 999, Tirol

59022-250 - Natal, RN - Brazil

Tel.: + 55 (84) 99929-8060/2030-4233

E-mail: paulaaborba@hotmail.com 